\title{
Familial predisposition to renal disease in two generations of Pima Indians with Type 2 (non-insulin-dependent) diabetes mellitus
}

\author{
D.J.Pettitt ${ }^{1}$, M.F.Saad ${ }^{1}$, P.H. Bennett ${ }^{1}$, R. G. Nelson ${ }^{2}$ and W.C. Knowler ${ }^{1}$ \\ ${ }^{1}$ Diabetes and Arthritis Epidemiology Section, Phoenix Epidemiology and Clinical Research Branch, National Institute of Diabetes and \\ Digestive and Kidney Diseases, National Institutes of Health, and ${ }^{2}$ Department of Biostatistics and Epidemiology, The Cleveland Clinic \\ Foundation, Phoenix, AZ, USA
}

\begin{abstract}
Summary. We studied the occurrence of renal disease by measuring serum creatinine and urine protein concentrations in the diabetic members of 316 Pima Indian families with Type 2 (non-insulin-dependent) diabetes in two successive generations to determine if diabetic renal disease aggregates in families. After adjustment for sex and other risk factors, proteinuria occurred among $14.3 \%$ of the diabetic offspring if neither parent had proteinuria, $22.9 \%$ if at least one diabetic parent had proteinuria, and $45.9 \%$ if both parents had diabetes and proteinuria. Among male offspring, an
\end{abstract}

elevated serum creatinine concentration $(\geq 177 \mu \mathrm{mol} / \mathrm{l})$ was present in $11.7 \%$ if the parent had an elevated creatinine and in $1.5 \%$ if the parent did not. Thus, proteinuria and high serum creatinine aggregated in diabetic families, suggesting that susceptibility to renal disease is inherited independently of diabetes.

Key words: Type 2 (non-insulin-dependent) diabetes mellitus, American Indians, diabetic renal disease, genetics.
End-stage renal disease, mostly attributable to diabetic nephropathy, is a major cause of morbidity and mortality for diabetic subjects [1-5]. Furthermore, among diabetic subjects, excessive mortality attributable to cardiovascular disease or infection, as well as to renal failure, occurs among those with proteinuria, which is the hallmark of diabetic nephropathy [6-8]. Duration of diabetes and degree of hyperglycaemia are major determinants of diabetic nephropathy [3, 4, 9-11], and yet many people have no evidence of renal disease even after many years of diabetes [12-14]. It has been observed that the incidence of proteinuria in Type 1 (insulin-dependent) diabetes mellitus increases rapidly after the first decade but diminishes later in the course of the disease [12,15], suggesting that not all subjects with diabetes are at risk of developing this complication. Several authors have suggested that susceptibility to renal disease in Type 1 diabetes may be hereditary [16-20], but this has not been shown to be the case in Type 2 (non-insulin-dependent) diabetes. It has been hypothesised that the susceptibility to diabetic renal disease may be inherited independently of diabetes $[2,10,17,20-$ 22], but that those who are susceptible develop renal complications only if they develop diabetes.

Because of the high prevalence and early age of onset of Type 2 diabetes in Pima Indians, there are many Pima families with diabetes in two generations. This circumstance enables examination of the hypothesis that among diabetic subjects there are familial determinants of renal disease that are perhaps attributable to differences in genetic susceptibility to renal disease. The aim of this study was to determine if diabetic renal disease in Pima Indians aggregates among parents and offspring with Type 2 diabetes.

\section{Subjects and methods}

The subjects are participants in the longitudinal study of diabetes which, since 1965, has been conducted in the Gila River Indian Community in Southern Arizona [23]. The residents of this community, who are primarily Pima or closely related Tohono O'odham (Papago) Indians, have the world's highest reported prevalence of Type 2 diabetes [24]. All residents of the community over the age of five years are asked, every two years, to participate in a standardised examination which includes the measurement of serum creatinine concentration and an oral glucose tolerance test. Plasma glucose was measured [25] on a specimen drawn $2 \mathrm{~h}$ after the ingestion of $75 \mathrm{~g}$ of carbohydrate (Glucola, Ames Co., Elkhart, Ind., USA; or Dexcola, Custom Laboratories, Baltimore, Md., USA). Subjects are asked to void before ingesting the carbohydrate, and a urine specimen is collected $2 \mathrm{~h}$ later at the end of the glucose tolerance test. This urine specimen was tested for protein by dipstick (Labstix, Ames Co.), and urine containing a trace or more of protein was tested quantitatively for protein using a precipitation technique [26]. Creatinine concentration was measured in the same urine samples using an automated alkaline picrate procedure [27]. The urine was not cultured. 
Table 1. Prevalence of proteinuria and high creatinine in offspring according to presence or absence of proteinuria and high creatinine in parents with Type 2 (non-insulin-dependent) diabetes

\begin{tabular}{llccc}
\hline Diabetic parents & Offspring & & \\
\cline { 2 - 5 } & Sex & Number of subjects & $\begin{array}{l}\text { Prevalence of proteinuria } \\
\text { number (\%) }\end{array}$ & $\begin{array}{l}\text { Prevalence of high creatinine } \\
\text { number }(\%)\end{array}$ \\
\hline No & Male & 77 & $19(25 \%)$ & $1(1 \%)$ \\
proteinuria & Female & 171 & $37(22 \%)$ & $6(4 \%)$ \\
Proteinuria onlyb & Male & 71 & $23(32 \%)$ & $3(4 \%)$ \\
& Female & 103 & $32(31 \%)$ & $2(2 \%)$ \\
Proteinuria and high & Male & 28 & $9(32 \%)$ & $4(14 \%)$ \\
creatinine $^{\mathrm{c}}$ & Female & 49 & $9(18 \%)$ & $0(0 \%)$ \\
Total & & 499 & $129(26 \%)$ & $16(3 \%)$ \\
${ }^{a}$ All subjects with high creatinine also had proteinuria; ${ }^{\mathrm{b}}$ In at least one parent, neither of whom had high creatinine; ${ }^{\mathrm{c}}$ In at least one parent
\end{tabular}

Blood pressure was measured, with the subject supine, with a large adult cuff and a mercury sphygmomanometer (W. A. Baum Co., Inc., Copiaque, NY, USA). The first and fourth Korotkoff sounds were used for systolic and diastolic pressures respectively.

All plasma, serum, and urine measurements were performed in the same laboratory using uniform methods throughout the study. Each assay, performed in duplicate, has included four (two normal and two abnormal) quality control specimens, and values for each control have met established criteria for the assay to be accepted. The laboratory has participated in proficiency testing of blinded samples supplied by the United States Centers for Disease Control or by the College of American Pathologists.

Diabetes was diagnosed according to the World Health Organisation criteria for epidemiologic studies [28] if the 2-h post-load venous plasma glucose concentration was at least $11.1 \mathrm{mmol} / 1$.

Two measures of renal disease were considered: (1) proteinuria, defined by a urine protein to urine creatinine ratio of at least one gramme of protein per gramme of creatinine, a level which corresponds to a urine protein excretion of approximately $1 \mathrm{~g} / 24 \mathrm{~h}[29$, $30]$; and (2) high creatinine, defined by a serum creatinine of at least $177 \mu \mathrm{mol} / \mathrm{l}$.

Pima and Tohono O'odham Indian families with diabetes in two successive generations were identified. Subjects who were half to full heritage Pima or Tohono O'odham Indians and who had diabetes of at least two years duration were eligible for inclusion. This duration was required to include only subjects who had had at least some time to develop proteinuria.

There were 316 families in which diabetes occurred in two successive generations and in which serum creatinine and urine protein concentrations had been measured after at least two years duration of diabetes. These families included 499 diabetic offspring (mean age, 44 years at their last examination) and 349 diabetic parents (mean age, 63 years). The 499 offspring included 133 for whom both parents had diabetes, 112 for whom both parents had been examined but only one had diabetes and the other did not, and 254 for whom one parent had diabetes of at least two years duration and one parent had not been examined or had diabetes of less than two years of duration.

Within the community but excluded from the analyses, i.e. not part of the 316 families, were five offspring who were less than half Pima and Tohono O'odham, seven whose diabetic parent had no data regarding proteinuria or serum creatinine concentration, and 71 because the offspring or parent had diabetes of less than two years duration. Also excluded were 11 offspring because proteinuria existed before the diagnosis of diabetes and three because the parent had proteinuria before the diagnosis of diabetes. Only 3 of these 14 had an identifiable cause (glomerulonephritis, chronic calcific cystitis, or nephrolithiasis) for their proteinuria. Within the community, but not included in present analyses, there were an additional 205 diabetic offspring, one or both of whose parents had been examined and did not have diabetes. Forty nine $(24 \%)$ of these 205 diabetic offspring had proteinuria and $15(7 \%)$ had an elevated creatinine.

\section{Statistical analysis}

Multiple logistic regression analysis [31] was used to compare the presence or absence of each of the two indicators of renal disease in the offspring and the diabetic parent while simultaneously controlling for age, sex, diabetes duration, plasma glucose concentration, and systolic blood pressure. These variables were chosen because of their univariate associations with renal disease. Models are shown with and without systolic blood pressure since elevated blood pressure may be a cause or a result of renal disease. Two indicator variables were used for parental proteinuria. The first indicator was given a value of ' 1 ' if either parent had proteinuria and ' 0 ' otherwise and served as an indication of the effect of the presence of proteinuria in one or both parents compared with neither parent having proteinuria. The second indicator variable was assigned a value of ' 1 ' only if both parents had proteinuria and ' 0 ' otherwise. This variable was an indication of the effect of both parents having proteinuria compared with only one having proteinuria. There were no cases in which both parents had an elevated creatinine so only one indicator variable was needed in the model evaluating the effect of a high creatinine in the parent. There were no significant interaction terms so such terms were not included in the final models presented. For each subject, the highest recorded 2-h post-load plasma glucose concentration was used as a measure of severity of diabetes. Blood pressure was used as a continuous variable in the model and was recorded without regard to antihypertensive medicine usage. For subjects with proteinuria, the blood pressure measured when proteinuria was first diagnosed and for other subjects, the value at the last examination, were used. Systolic and diastolic blood pressure were highly correlated and only systolic, the stronger of the two predictors, was used in the models. Odds ratios were calculated as described by Kleinbaum et al. [32]. Covariate-adjusted prevalence rates of proteinuria and elevated creatinine in the offspring of parents with and without these complications were calculated from the regression model by covariance adjustment of rates to the mean values of the covariates in the sample [33].

\section{Results}

Table 1 shows prevalence of proteinuria and high creatinine in diabetic offspring according to the presence of proteinuria or elevated creatinine in the diabetic parents. Proteinuria was present in $25.9 \%$ of the offspring $(29.0 \%$ in males and $24.1 \%$ in females). Half $(50.3 \%)$ of the offspring had at least one diabetic parent with proteinuria. Elevated creatinine was present in $3.2 \%$ of the offspring and $15.4 \%$ had a diabetic parent with a high creatinine. All subjects with elevated creatinine concentrations also had proteinuria. 
Table 2. Prevalence (\%) of proteinuria in offspring according to age, duration of Type 2 (non-insulin-dependent) diabetes, 2 -h post-load plasma glucose concentration and systolic and diastolic blood pressure by number of diabetic parents with proteinuria

\begin{tabular}{|c|c|c|c|c|c|c|}
\hline & \multicolumn{6}{|c|}{ Number of parents with proteinuria } \\
\hline & \multicolumn{2}{|c|}{ None } & \multicolumn{2}{|l|}{ One } & \multicolumn{2}{|c|}{ Two } \\
\hline & $\bar{n}$ & Prevalence in offspring & $n$ & Prevalence in offspring & $n$ & Prevalence in offspring \\
\hline \multicolumn{7}{|c|}{ Age (years) } \\
\hline $\begin{array}{l}<35 \\
35-54 \\
\geq 55\end{array}$ & $\begin{array}{r}56 \\
130 \\
61\end{array}$ & $\begin{array}{l}12.5 \\
18.5 \\
39.3\end{array}$ & $\begin{array}{r}72 \\
132 \\
36\end{array}$ & $\begin{array}{l}13.9 \\
33.3 \\
41.7\end{array}$ & $\begin{array}{l}6 \\
5 \\
1\end{array}$ & $\begin{array}{r}16.7 \\
60.0 \\
100.0\end{array}$ \\
\hline \multicolumn{7}{|c|}{ Diabetes duration (years) } \\
\hline $\begin{array}{l}<5 \\
5-9 \\
10-14 \\
\geq 15\end{array}$ & $\begin{array}{l}47 \\
74 \\
54 \\
72\end{array}$ & $\begin{array}{r}12.8 \\
9.5 \\
13.0 \\
48.6\end{array}$ & $\begin{array}{l}52 \\
67 \\
55 \\
66\end{array}$ & $\begin{array}{r}7.7 \\
11.9 \\
34.5 \\
57.6\end{array}$ & $\begin{array}{l}3 \\
2 \\
4 \\
3\end{array}$ & $\begin{array}{r}0.0 \\
0.0 \\
50.0 \\
100.0\end{array}$ \\
\hline \multicolumn{7}{|c|}{ 2-h glucose $(\mathrm{mmol} / \mathrm{l})$} \\
\hline $\begin{array}{l}<16 \\
16-22 \\
22-28 \\
\geq 28\end{array}$ & $\begin{array}{r}37 \\
51 \\
100 \\
59\end{array}$ & $\begin{array}{r}5.4 \\
11.8 \\
18.0 \\
49.2\end{array}$ & $\begin{array}{r}33 \\
50 \\
103 \\
54\end{array}$ & $\begin{array}{r}9.1 \\
10.0 \\
29.1 \\
57.4\end{array}$ & $\begin{array}{l}3 \\
3 \\
4 \\
2\end{array}$ & $\begin{array}{r}0.0 \\
33.3 \\
50.0 \\
100.0\end{array}$ \\
\hline \multicolumn{7}{|c|}{ Systolic blood pressure $(\mathrm{mm} \mathrm{Hg})$} \\
\hline $\begin{array}{l}<120 \\
120-159 \\
\geq 160\end{array}$ & $\begin{array}{r}88 \\
143 \\
16\end{array}$ & $\begin{array}{r}9.1 \\
25.9 \\
62.5\end{array}$ & $\begin{array}{r}94 \\
123 \\
23\end{array}$ & $\begin{array}{l}11.7 \\
35.0 \\
65.2\end{array}$ & $\begin{array}{l}3 \\
8 \\
1\end{array}$ & $\begin{array}{r}33.3 \\
37.5 \\
100.0\end{array}$ \\
\hline \multicolumn{7}{|c|}{ Diastolic blood pressure (mm Hg) } \\
\hline $\begin{array}{l}<80 \\
80-99 \\
\geq 100\end{array}$ & $\begin{array}{r}141 \\
91 \\
15\end{array}$ & $\begin{array}{l}13.5 \\
30.8 \\
53.3\end{array}$ & $\begin{array}{r}130 \\
99 \\
11\end{array}$ & $\begin{array}{l}17.7 \\
38.4 \\
72.7\end{array}$ & $\begin{array}{l}7 \\
5 \\
0\end{array}$ & $\begin{array}{l}42.9 \\
40.0 \\
-\end{array}$ \\
\hline
\end{tabular}

The prevalence of proteinuria in the offspring varied with age, duration of diabetes, severity of diabetes as measured by the 2-h post-load plasma glucose concentration, and with blood pressure (Table 2). In most strata, the prevalence in the offspring was higher if one or both diabetic parents had proteinuria and lowest if neither parent had proteinuria. Table 3 shows the odds ratios from the logistic models used to control for the covariates. Proteinuria in the offspring was associated with proteinuria in the parents and with diabetes duration and 2-h post-load plasma glucose concentration of the offspring. Systolic blood pressure was associated with proteinuria but its addition to the model had little effect on the odds ratios of the other variables. Proteinuria was crudely associated with age, but after being controlled for diabetes duration, there was no association.

Figure 1 shows the covariate-adjusted prevalence of proteinuria in the offspring, estimated from the data shown in Table 3, according to sex and to proteinuria in the diabetic parents. Offspring with at least one diabetic parent with proteinuria had a significantly higher prevalence of proteinuria $(22.9 \%)$ than did the offspring of diabetic parents without proteinuria $(14.3 \%$, odds ratio $=1.8,95 \%$ confidence interval $=1.1$ to 2.9 , $(p=0.019)$ controlled for age, sex, diabetes duration, and 2-h post load plasma glucose concentration with logistic regression). The adjusted prevalence of proteinuria was even higher in the offspring who had two diabetic parents with proteinuria $(45.9 \%)$ than the offspring with one parent with proteinuria $(22.9 \%)$, however, the odds ratio of 2.9 (for the effect of having two compared with one diabetic parent with proteinuria) has wide $95 \%$ confidence limits of 0.7 and 12.1 .

Elevated creatinine, unlike proteinuria, was much more prevalent in male than in female offspring. Because of the sex difference, males and females were analysed separately. Of 323 females with diabetic parents, elevated creatinine occurred in only eight, all of whom were among the 274 offspring of parents without elevated creatinine. On the other hand, $14.3 \%$ ( 4 of 28 ) of the male offspring of parents with elevated creatinine had elevated creatinine

Table 3. Results of multiple logistic regression models. Age, sex, diabetes duration, glucose concentration, and blood pressure are offspring variables. Dependent variable: proteinuria in offspring

\begin{tabular}{lll}
\hline Variable & Odds ratio $^{\mathrm{a}}$ & 95\% C.I. \\
\hline Model $A$ & & \\
Proteinuria in either parent (0 or 1) & 1.8 & $1.1-2.9$ \\
Proteinuria in 2nd parent (0 or 1) & 2.9 & $0.7-12.1$ \\
Age (per 5 years) & 1.0 & $0.9-1.2$ \\
Male sex & 1.6 & $1.0-2.6$ \\
Type 2 diabetes duration (per 5 years) & 1.8 & $1.5-2.3$ \\
2-h glucose (per 2.5 mmol/ $)$ & 1.4 & $1.3-1.6$ \\
Model $B$ & & \\
Proteinuria in either parent (0 or 1) & 1.9 & $1.1-3.1$ \\
Proteinuria in 2nd parent (0 or 1) & 2.5 & $0.6-11.2$ \\
Age (per 5 years) & 1.0 & $0.9-1.1$ \\
Male sex & 1.1 & $0.9-1.1$ \\
Type 2 diabetes duration (per 5 years) & 1.8 & $1.4-2.2$ \\
2-h glucose (per 2.5 mmol/1) & 1.4 & $1.2-1.5$ \\
Systolic blood pressure (per 10 mm $\mathrm{Hg}$ ) & 1.4 & $1.2-1.6$ \\
\hline
\end{tabular}

${ }^{a}$ Odds ratio for number of units shown in parentheses; ${ }^{b}$ C.I. $=$ confidence interval 


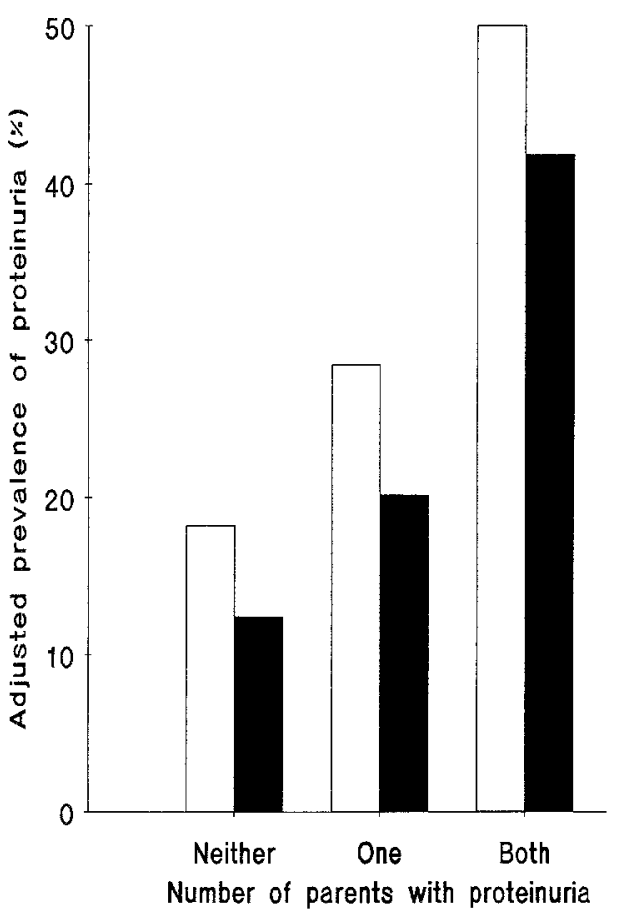

Fig.1. Prevalence of proteinuria in offspring according to sex and number of parents with proteinuria, adjusted for age, systolic blood pressure, diabetes duration, and glucose concentration. (Open bars $=$ males, solid bars $=$ females $)$

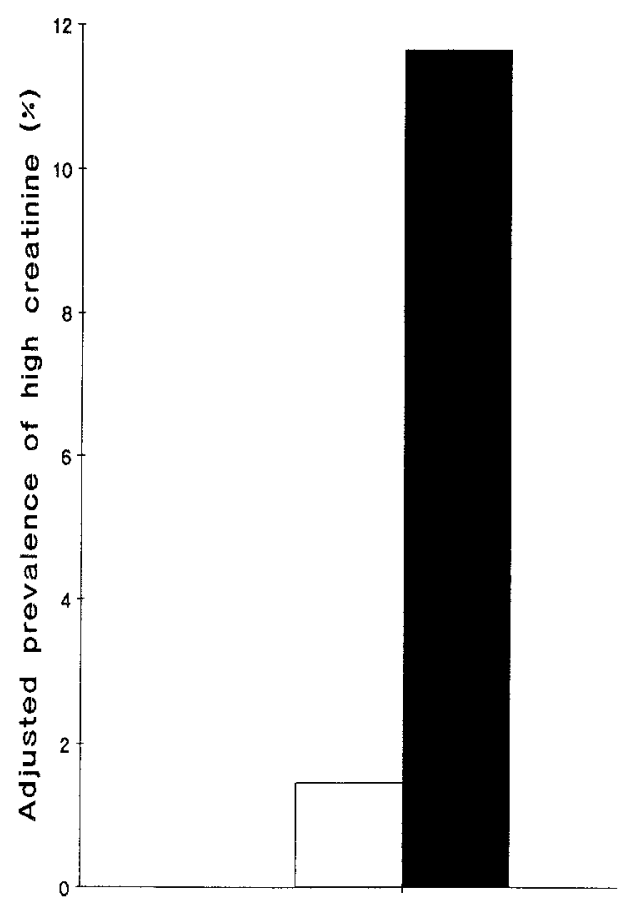

Fig. 2. Prevalence of elevated creatinine in male offspring, adjusted for age, systolic blood pressure, diabetes duration, and glucose concentration. (Open bar = offspring of parents without elevated creatinine, solid bar = offspring of parents with elevated creatinine)

compared with $2.7 \%$ ( 4 of 148) of the offspring of parents without elevated creatinine $(p<0.023,2$-tailed Fisher's exact test.

Among male offspring (Table 4), the prevalence of elevated creatinine varied with age, diabetes duration, 2-h post-load glucose concentration, and blood pressure, and was generally higher in the offspring of parents with elevated creatinine. Figure 2 shows that the adjusted prevalence of elevated creatinine was much higher in the male offspring of diabetic parents who had elevated creatinine $(11.7 \%)$ than in the offspring of diabetic parents who did not have elevated creatinine $(1.5 \%)$. Table 5 shows the regression coefficients and odds ratios for the variables included in the models. The estimate of the odds ratio is 8.9 with $95 \%$ confidence limits of 1.6 and 49.1 (adjusted for age, 2-h post-load plasma glucose concentration and duration of diabetes). Blood pressure, when added to the model, was significantly $(p=0.001)$ associated with a high creatinine. With blood pressure, the estimate for the odds ratio for the parental effect was reduced slightly to 6.5 with confidence limits of 0.7 and 62.5 indicating that the difference in blood pressure accounts for some of the difference in the prevalence of an elevated creatinine concentration between the offspring of parents with and without an elevated creatinine and suggesting that, in part, the parental effect may be mediated by blood pressure.

\section{Discussion}

The high prevalence of Type 2 diabetes in the Pima Indians and the follow-up of the population for 25 years have allowed the occurrence of diabetic renal disease to be evaluated in two successive generations. Diabetic offspring who had parents with diabetic renal disease were at higher risk for renal disease than offspring of diabetic parents without renal disease. This demonstrates that diabetic renal disease aggregates in families and suggests that the development of renal disease among those with Type 2 diabetes is determined independently of the susceptibility to diabetes. In Type 1 diabetes, only about $50 \%$ of diabetic subjects develop renal disease and the incidence of this complication is highest in the first 15 to 30 years of diabetes, after which time it diminishes [12, 15]. Furthermore, it has been claimed that renal disease aggregates in siblings with Type 1 diabetes [18]. These observations have led to speculation that susceptibility to diabetic renal disease is common but is inherited independently from diabetes and is expressed only in those who have diabetes. The present study supports the same hypothesis in Type 2 diabetes.

If renal disease were an inevitable complication of diabetes, its incidence might be expected to be a simple function of duration and severity of diabetes. We have previously shown that blood pressure is also an important predictor of the development of proteinuria among Pima Indians with Type 2 diabetes $[11,34]$. In the present study blood pressure in the offspring was significantly associated with both clinical proteinuria and elevation of the serum creatinine concentration. Although blood pressure and the duration and severity of hyperglycaemia are important determinants, the present study shows in addition, that in subjects with Type 2 diabetes the occurrence of renal disease in parents confers an increased risk of renal disease in the offspring. 
Parental hypertension is associated with renal disease in subjects with Type 1 diabetes, suggesting that an inherited factor not necessarily related to diabetes per se influences the development of nephropathy $[19,20]$. On the other hand, Mathiesen et al. [35] have shown that in Type 1 diabetes, by the time blood pressure is elevated, albumin excretion is already abnormal. They suggested that elevated blood pressure may be a very early manifestation of renal disease in diabetes. Although in the present study, parental blood pressure, often measured many years after diabetes had developed, was not related to renal disease in the offspring (data not shown), the blood pressure in the parents may have been altered by therapy and by the presence of diabetes or diabetic nephropathy. Furthermore, the effect of proteinuria in the parents as a risk factor for proteinuria in the offspring remained after being adjusted for blood pressure, although the parental effect on the elevated creatinine was somewhat diminished. Thus, the additional risk of renal disease attributable to parental renal disease is not entirely an effect mediated by blood pressure.

Familial aggregation of elevated serum creatinine concentration was examined as an index of a more serious degree of diabetic nephropathy. Renal insufficiency, reflected by such increases in serum creatinine, has a serious prognosis and heralds the development of renal failure and end-stage renal disease. Many subjects with proteinuria will develop renal insufficiency $[4,5]$, and the familial aggregation of proteinuria found in the present study might be expected to lead to familial aggregation of renal insufficiency and end-stage renal disease. Although proteinuria occurred more frequently in both men and women when the parents had proteinuria, the prevalence of an elevated serum creatinine was low in the younger generation of women, and not significantly associated with elevated creatinine in the parents. Although there are reports of a higher prevalence of microangiopathic complications of diabetes in men than in women $[2,12$, 16], the sex difference in elevated serum creatinine concentrations in the offspring in this study is most likely due to the small sample size, as Pima women and men have similar incidence rates of end-stage renal disease [4], and among the diabetic parents in the present study $12 \%$ (29 of 238 ) of the mothers and $8 \%$ of the fathers ( 9 of 111) had serum creatinine concentrations of $177 \mu \mathrm{mol} / \mathrm{l}$ or greater. Among diabetic offspring who were excluded, the prevalence of an elevated creatinine was similar in males $(7.9 \%)$ and females $(7.0 \%)$ making selection bias an unlikely explanation for the sex difference.

The definitions of renal disease used in this study, while highly specific, are not sensitive, and some parents and offspring may have been misclassified. Some of the diabetic offspring may have had renal disease unrelated to their diabetes, although given the relative frequency of renal disease among diabetic compared with non-diabetic Pima Indians [4, 11], this probably contributed only a small fraction of those affected. Also, the fact that subjects were classified as to renal disease cross-sectionally only as of the last biennial research examination may have introduced a bias that would tend to result in underestimation of the extent of familial aggregation of renal disease. From
Table 4. Prevalence (\%) of high creatinine in male offspring according to age, duration of Type 2 (non-insulin-dependent) diabetes, 2-h post-load plasma glucose concentration and systolic and diastolic blood pressure by absence or presence of high creatinine in the diabetic parents

\begin{tabular}{|c|c|c|c|c|}
\hline & \multicolumn{4}{|c|}{ Parental high creatinine } \\
\hline & \multicolumn{2}{|c|}{ Absent } & \multicolumn{2}{|c|}{ Present } \\
\hline & $\bar{n}$ & $\begin{array}{l}\text { Prevalence } \\
\text { in offspring }\end{array}$ & $n$ & $\begin{array}{l}\text { Prevalence } \\
\text { in offspring }\end{array}$ \\
\hline \multicolumn{5}{|c|}{ Age (years) } \\
\hline $\begin{array}{l}<35 \\
35-54 \\
\geq 55\end{array}$ & $\begin{array}{l}40 \\
83 \\
25\end{array}$ & $\begin{array}{l}0.0 \\
3.6 \\
4.0\end{array}$ & $\begin{array}{r}7 \\
20 \\
1\end{array}$ & $\begin{array}{r}0.0 \\
20.0 \\
0.0\end{array}$ \\
\hline \multicolumn{5}{|c|}{ Diabetes duration (years) } \\
\hline $\begin{array}{l}<5 \\
5-9 \\
10-14 \\
\geq 15\end{array}$ & $\begin{array}{l}33 \\
42 \\
29 \\
44\end{array}$ & $\begin{array}{l}0.0 \\
0.0 \\
3.4 \\
6.8\end{array}$ & $\begin{array}{l}8 \\
8 \\
7 \\
5\end{array}$ & $\begin{array}{r}0.0 \\
12.5 \\
14.3 \\
40.0\end{array}$ \\
\hline \multicolumn{5}{|c|}{2 -h glucose $(\mathrm{mmol} / 1)$} \\
\hline $\begin{array}{l}<16 \\
16-22 \\
22-28 \\
\geq 28\end{array}$ & $\begin{array}{l}20 \\
36 \\
56 \\
36\end{array}$ & $\begin{array}{l}0.0 \\
2.8 \\
3.6 \\
2.8\end{array}$ & $\begin{array}{r}3 \\
11 \\
11 \\
3\end{array}$ & $\begin{array}{r}33.3 \\
9.1 \\
9.1 \\
33.3\end{array}$ \\
\hline \multicolumn{5}{|c|}{ Systolic blood pressure $(\mathrm{mm} \mathrm{Hg})$} \\
\hline $\begin{array}{l}<120 \\
120-159 \\
\geq 160\end{array}$ & $\begin{array}{l}41 \\
93 \\
14\end{array}$ & $\begin{array}{r}0.0 \\
1.1 \\
21.4\end{array}$ & $\begin{array}{r}5 \\
19 \\
4\end{array}$ & $\begin{array}{r}0.0 \\
5.3 \\
75.0\end{array}$ \\
\hline \multicolumn{5}{|c|}{ Diastolic blood pressure ( $\mathrm{mm} \mathrm{Hg}$ ) } \\
\hline $\begin{array}{l}<80 \\
80-99 \\
\geq 100\end{array}$ & $\begin{array}{l}59 \\
75 \\
14\end{array}$ & $\begin{array}{l}1.7 \\
2.7 \\
7.1\end{array}$ & $\begin{array}{r}8 \\
18 \\
2 \\
\end{array}$ & $\begin{array}{r}0.0 \\
16.7 \\
50.0 \\
\end{array}$ \\
\hline
\end{tabular}

Table 5. Results of multiple logistic regression models. Age, diabetes duration, glucose concentration, and blood pressure are offspring variables. Dependent variable: High creatinine in male offspring

\begin{tabular}{lll}
\hline Variable & Odds ratio $^{\mathrm{a}}$ & 95\% C. I. \\
\hline Model $A$ & & \\
Parental high creatinine (0 or 1) & 8.9 & $1.6-49.1$ \\
Age (per 5 years) & 1.0 & $0.6-1.5$ \\
Type 2 diabetes duration (per 5 years) & 2.3 & $1.1-4.7$ \\
2-h glucose (per 2.5 mmol/1) & 1.1 & $0.8-1.5$ \\
Model B & & \\
Parental high creatinine (0 or 1) & 6.5 & $0.7-62.5$ \\
Age (per 5 years) & 0.7 & $0.4-1.5$ \\
Type 2 diabetes duration (per 5 years) & 2.3 & $0.9-2.5$ \\
2-h glucose (per 2.5 mmol/ $)$ & 1.1 & $0.7-1.6$ \\
Systolic blood pressure (per 10 $\mathrm{mm} \mathrm{Hg})$ & 2.6 & $1.5-4.6$ \\
\hline
\end{tabular}

${ }^{a}$ Odds ratio for number of units shown in parentheses; ${ }^{b}$ C. I. $=$ confidence interval

the available data, it is not possible to say if the familial predisposition to renal disease is a result of genetic predisposition, of some unknown familial environmental factors, or both.

Despite these limitations, a strong familial association of both proteinuria and elevated creatinine was found. The strength of this association suggests that genetic transmission of susceptibility to renal disease may be the most likely explanation for the findings. 
Acknowledgements. We thank the members of the Gila River Indian Community who have participated in the longitudinal study over the past 25 years and the staff of the Phoenix Epidemiology and Clinical Research Branch for collecting and processing the data.

\section{References}

1. Eggers PW, Connerton R, McMullan M (1984) The medicare experience with end-stage renal disease: trends in incidence, prevalence, and survival. Health Care Financing Review 5: 69-88

2. Moloney A, Tunbridge WMG, Ireland JT, Watkins PJ (1983) Mortality from diabetic nephropathy in the United Kingdom. Diabetologia 25: 26-30

3. Kamenetzky SA, Bennett PH, Dippe SE, Miller M, LeCompte PM (1974) A clinical and histologic study of diabetic nephropathy in the Pima Indians. Diabetes 23: 61-68

4. Nelson RG, Newman JM, Knowler WC, Sievers ML, Kunzelman CL, Pettitt DJ, Moffett CD, Teutsch SM, Bennett PH (1988) Incidence of end-stage renal disease in Type 2 (non-insulin-dependent) diabetes mellitus in Pima Indians. Diabetologia 31: $730-736$

5. Nelson RG, Pettitt DJ, Carraher MJ, Baird HR, Knowler WC (1988) Effect of proteinuria on mortality in Type 2 diabetes. Diabetes 37: 1499-1504

6. Parving H-H, Oxenbøll B, Svendsen PA, Christiansen JS, Andersen AR (1982) Early detection of patients at risk of developing diabetic nephropathy. A longitudinal study of urinary albumin excretion. Acta Endocrinol 100: 550-555

7. Viberti GC, Hill RD, Jarrett RJ, Argyropoulos A, Mahmud U, Keen H (1982) Microalbuminuria as a predictor of clinical nephropathy in insulin-dependent diabetes mellitus. Lancet I: 1430-1432

8. Mogensen CE, Christensen CK (1986) Predicting diabetic nephropathy in insulin-dependent patients. N Engl J Med 311: 89 93

9. West KM, Erdereich LJ, Stober JA (1980) A detailed study of risk factors for retinopathy and nephropathy in diabetes. Diabetes 29: 501-508

10. Mijovic C, Fletcher JA, Bradwell AR, Barnett AH (1986) Phenotypes of the heavy chains of immunoglobulins in patients with diabetic microangiopathy: evidence for an immunogenetic predisposition. Br Med J 292: 433-435

11. Kunzelman CL, Knowler WC, Pettitt DJ, Bennett PH (1989) Incidence of proteinuria in type 2 diabetes mellitus in the Pima Indians. Kidney Int 35: 681-687

12. Andersen AR, Christiansen JS, Andersen JK, Kreiner S, Deckert T (1983) Diabetic nephropathy in Type 1 (insulin-dependent) diabetes: an epidemiological study. Diabetologia 25: 496-501

13. Christlieb AR, Krolewski AS, Warram JH (1987) Systemic hypertension, diabetes mellitus and the kidney. Am J Cardiol 60: $61 \mathrm{I}-65 \mathrm{I}$

14. Editorial (1988) What causes diabetic renal failure? Lancet I: 1433-1434

15. Krolewski AS, Warram JH, Christlieb AR, Busick EJ, Kahn CR (1985) The changing natural history of nephropathy in type I diabetes. Am J Med 78: 785 794

16. Barbosa J, Saner B (1984) Do genetic factors play a role in the pathogenesis of diabetic microangiopathy? Diabetologia 27: 487492

17. Seaquist ER, Goetz FC, Povey S (1986) Diabetic nephropathy: an hypothesis regarding genetic susceptibility for the disorder. Minnesota Medicine 69: 457-459
18. Seaquist E, Goetz F, Rich S, Barbosa J (1989) Familial clustering of diabetic kidney disease: evidence for genetic susceptibility to diabetic nephropathy. N Engl J Med 320: 1161-1165

19. Viberti GC, Keen H, Wiseman MJ (1987) Raised arterial pressure in parents of proteinuric insulin dependent diabetics. $\mathrm{Br}$ Med J 295: 515-517

20. Krolewski AS, Canessa M, Warram JH, Laffel LMB, Christlieb AR, Knowler WC, Rand LI (1988) Predisposition to hypertension and susceptibility to renal disease in insulin-dependent diabetes mellitus. N Engl J Med 318: 140-145

21. Chobanian MC, Chevalier RL, Sturgill BC, Bolton WK (1984) Early onset of clinical diabetic nephropathy in children - a new subgroup? Int J Ped Nephrol 5:23-29

22. Barnett AH, Pyke DA (1986) The genetics of diabetic complications. Clin Endocrinol Metab 15: 715-726

23. Bennett PH, Burch TA, Miller M (1971) Diabetes mellitus in American (Pima) Indians. Lancet II: 825-828

24. Knowler WC, Bennett PH, Hamman RF, Miller M (1978) Diabetes incidence and prevalence in Pima Indians: a 19-fold greater incidence than in Rochester Minnesota. Am J Epidemiol 108: 497-505

25. Technicon Autoanalyzer method File N.2b. (1965) Technicon Instruments Corporation, Tarrytown, N. Y.

26. Shevky MC, Stafford DD (1923) A clinical method for the estimation of protein in urine and other body fluids. Arch Int Med 32: $222-225$

27. Chasson AL, Grady HJ, Stanley MA (1961) Determination of creatinine by means of automatic chemical analysis. Am J Clin Pathol 35: 83-88

28. WHO Study Group (1985) Diabetes mellitus. World Health Organization, Geneva pp 9-17 (Tech Rep Ser 727)

29. Ginsberg JM, Chang BS, Matarese RA, Garella S (1983) Use of single voided urine samples to estimate quantitative proteinuria. N Engl J Med 309: 1543-1546

30. Shaw AB, Risdon P, Lewis-Jackson JD (1983) Protein creatinine index and Albustix in assessment of proteinuria. Br Med $\mathbf{J} 287$ : 929-932

31. Conceptual Software, Inc. (1987) Prodas Reference Manual Version 3.2 A. Conceptual Software, Inc., Houston, Tex.

32. Kleinbaum DG, Kupper LL, Morgenstern H (1982) Epidemiologic research: principles and quantitative methods. Van Nostrand Reinhold, New York Berkshire Melbourne Ontario, pp 419-446

33. Lee J (1981) Covariance adjustment of rates based on the multiple logistic regression model. J Chronic Dis 34: 415-426

34. Knowler WC, Bennett PH, Nelson RG, Saad MF, Pettitt DJ (1988) Blood pressure before the onset of diabetes predicts albuminuria in Type 2 (non-insulin-dependent) diabetes. Diabetologia 31: 509 (Abstract)

35. Mathiesen ER, Rønn B, Jensen T, Storm B, Deckert T (1990) Relationship between blood pressure and urinary albumin excretion in development of microalbuminuria. Diabetes 39: 245-249

Received: 28 August 1989

and in revised form: 20 February 1990

Dr. D.J.Pettitt

Diabetes and Arthritis Epidemiology Section

NIDDK

1550 East Indian School Road

Phoenix, Arizona 85014

USA 